\title{
Frugal-IDeM: An Integrated Methodology for Designing Frugal Innovations in Low-Resource Settings
}

\author{
Santosh Jagtap
}

\begin{abstract}
People living in low-resource settings at the base of the world income pyramid (i.e. Base of the Pyramid - BOP) face several constraints. To satisfy their unmet needs, integrated frugal innovations are necessary. Several studies, discussed using many names such as 'design for Base of the Pyramid', 'design for development', 'product service systems', ‘frugal innovations', 'humanitarian engineering', 'appropriate technology', etc., have explored the design of such integrated frugal innovations for the BOP. Based on ten key design aspects, gleaned from such studies, this paper aims at

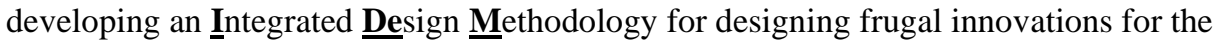
BOP (Frugal-IDeM). We have related the key design aspects with the various phases in the design and development process. The Frugal-IDeM also includes recommendations for how to implement the key design aspects.
\end{abstract}

Keywords Design process, Integrated Design, Product Service Systems, Base of the Pyramid, Frugal Innovations, Low-Resource Settings

\section{Introduction}

People living in low-resource settings at the Base of the Pyramid (BOP) face many problems such as lack of income generation opportunities and poor access to basic facilities such as healthcare, education, clean drinking water, etc. (e.g. Prahalad, 2004). Design, with its central idea of changing an existing situation into a desired situation, is essential to alleviate problems of BOP people (Jagtap, 2019a). Appropriately designed frugal innovations can potentially satisfy their needs (Aranda-Jan et al., 2016). Such frugal innovations include, for example, water and sanitation facilities, systems providing access to healthcare services, etc.

Frugal innovations for satisfying unmet or underserved needs of BOP societies need to address many different constraints such as poor physical infrastructure, shortage of resources, illiteracy of BOP people, and their low income (UNDP, 2008). Therefore, activities of designing such innovations must address several requirements and deprivations in these societies, resulting into holistic solutions (e.g. Product Service Systems - PSS). Such holistic, integrated innovations include, for example, appropriate systems to address the problem of weak distribution channels or they may include suitable systems to repair implemented products (Jagtap and Larsson, 2019; UNDP, 2008).

\footnotetext{
S. Jagtap

Blekinge Institute of Technology, Sweden

e-mail: santosh.jagtap@iitb.ac.in; snjagtap22@gmail.com
}

International Conference on Research into Design, ICoRD 2021, IIT Bombay, Mumbai, India 
Whilst some authors have proposed design methodologies for developing integrated innovations in the context of Western countries, there is absence of such design methodologies for the BOP context (e.g. Jagtap, 2019b). Since design is context-specific, there is a profound need of developing integrated design methodologies, specifically tailored to the BOP. The objective of this study is to develop an Integrated Design Methodology (IDeM) for designing frugal innovations to satisfy unmet or underserved needs of BOP people. We call this methodology as Frugal-IDeM. The Frugal-IDeM is based on key aspects of designing integrated frugal innovations for the BOP, gleaned from the analysis of several studies undertaken in the BOP context. The research methodology used for searching and analysing these studies is available in our previous study (Jagtap, 2019b). Following this introduction, the rest of the paper is organised as follows. Whilst Section 2 presents key design aspects, they are synthesized in the form of an integrated methodology in Section 3. Finally, Section 4 presents conclusions.

\section{Key Aspects of the Integrated Design Methodology}

There are several models of design and development processes. In general, the process of designing and developing innovations consists of the phases (e.g. Jagtap, 2019c): (1) project planning and task clarification (e.g., contextual understanding, need-identification); (2) conceptual and detail design (e.g., generation and evaluation of concepts, detail design); and (3) realisation and implementation (e.g., testing, manufacturing, maintenance, etc.). This section presents the ten keys aspects of designing integrated frugal innovations for the BOP, and relates these aspects to above-mentioned phases of the design and development process.

\subsection{Holistic contextual understanding}

BOP societies face many different problems. Several scholars have devised taxonomies to categorize these problems. Some scholars have classified them into individual, institutional, infrastructural and technological categories (e.g., Aranda Jan et al., 2016), whereas others gave organised them into economic-, psychosocial-, physical-, and knowledge-deprivations (e.g., Nakata and Weidner, 2012). Therefore, satisfying needs of BOP societies demands identifying and addressing many problems. Innovations designed for these societies must be based on comprehensive contextual understanding of various issues in these societies.

Several scholars have offered methods for developing and establishing comprehensive understanding of the target context. For example, Aranda-Jan et al. (2016) developed a method called 'holistic design framework' to support designers in understanding the target context. Another method is POEMS (people, objects, environments, messages, and services) framework (Whitney and Kelkar, 2004). It is essential to develop comprehensive understanding of the context early in the design process - that is - in the project planning and task clarification phase (see Figure 1a). 


\subsection{User involvement}

Innovations designed without involving BOP people in the design process may not be adopted and used on sustained basis when the teams developing those innovations leave the community or begin working on some other projects (e.g., Nieusma, 2004). Outsiders, living in developed countries or relatively wealthy areas of developing countries, are typically unfamiliar with the lives of BOP people and their circumstances. Therefore, involvement of BOP people in design activities is necessary not only to overcome their unfamiliarity about life circumstances of BOP people, but also to enhance the probability of continued usage of implemented innovations by the BOP people (e.g. Jagtap, 2019a).

Several studies have offered recommendations for how to involve BOP people in design and development activities. It is crucial to recognise that BOP people have expertise in living in low resource settings, and have in-depth knowledge of local networks and resources (e.g. Murcott, 2007). Drawing, pictures, and narrative methods of communication support involvement of BOP people in design activities. Since involving BOP people supports several activities such as conceptual and detail design as well as realisation and implementation of innovations, the activities related to their involvement need to be undertaken in all phases of the process (see Figure 1b).

\subsection{Innovation adaptation}

Adapting innovations to the specificities of BOP communities is essential for their continued adoption and use by the BOP people (Jagtap, 2019b). Ernst et al.'s (2015) and UNDP's (2008) large scale empirical studies, undertaken in various sectors such as healthcare, energy, transportation and in various regions, highlight the crucial role of adapting innovations to the BOP specificities. The diversity across BOP contexts demands adapting innovations to the needs and circumstance of a specific context.

Another recommendation found in the literature is to synergistically adapt various parts of the innovation (e.g., products, necessary networks, services, etc.) to tailor the entire innovation for a specific BOP context (e.g., Devisscher and Mont, 2008). Visual comprehensibility, interpersonal marketing, affordability, atomized distribution, and flexible payment schemes can enhance adaptability of designed innovations to the specific requirements of a BOP context. Implementing holistic contextual understanding, gleaned in the project planning and task clarification phase, to tailor innovations to the target context of the BOP communities needs to be carried out in conceptual and detail design phase. Therefore, the activities of adapting innovations to the local context are mainly undertaken in the conceptual and detail design phase (see Figure 1c).

\subsection{Drawing on local strengths}

Because BOP societies face many different constraints and deprivations, they exhibit peculiar socio-cultural characteristics. For instance, the values of sharing resources are not uncommon among BOP communities (e.g., Jagtap and Larsson, 2013). They typically give priority to building trusting relationships over business transactions. Previous studies have found that drawing on the strengths of BOP societies is a key strategy in 
designing innovations in this field (e.g. UNDP, 2008). Besides drawing on socio-cultural strengths of BOP societies, many studies suggest building on existing available resources, supporting the attempts of reducing costs and enhancing affordability (e.g., Prahalad, 2004).

Previous studies have offered recommendation for how to build on strengths of BOP communities. Leveraging strengths of BOP societies demands identifying their strengths. Social embeddedness supports design teams in gaining deep understanding of various socio-cultural strengths and resources available in these communities. Some studies also suggest creatively building on the identified strengths of BOP societies. For example, designed innovations can use sharing culture and available products available in BOP societies (e.g., Jagtap et al., 2013). The activities of building on these strengths are predominantly undertaken in conceptual and detail design phase (see Figure 1e).

\subsection{Context-specific training plans}

Designing innovations for the betterment of BOP societies requires many inputs from several actors. These actors may lack all the knowledge and skills required to design, develop, implement the innovation (e.g., López et al., 2017). Training these actors to build and enhance their knowledge and skills in some specific areas is therefore essential. For example, training programmes are essential to overcome BOP people's illiteracy and lack of required skills to perform some design activities or to implement and maintain innovations. In a similar fashion, suitable training programmes can be necessary to train other stakeholders. Jagtap et al.'s (2013) study, analysing many design cases, found that most of the cases employed training to support involved stakeholders.

Some studies suggest training a few local people in the initial phase, and then employing them to train others in the community (e.g. Devisscher and Mont, 2008). This strategy builds on the language skills of the local trainers and their knowledge about cultural norms acceptable in the local community. Factors such as age, gender, educational level of trainees ought to be considered (Jagtap et al., 2013). Programmes designed to train BOP people need to be local, concrete and social. The activities of designing and implementing training plans need to be considered throughout the design process (see Figure 1d).

\subsection{Income generation opportunities}

Income is a key dimension of resource scarcity in BOP communities. Increasing income is an effective alternative to address their problems. BOP people prefer income generating solutions. For example, a study, examining the design of an irrigation system, found that low-income farmers participated in the implementation of those systems as they were aimed at increasing their agricultural productivity and thus their income (Jagtap and Larsson, 2019).

Some studies recommend creating income generation opportunities by employing BOP people to address functions such as manufacturing, maintenance, etc. (e.g., Letaifa and Reynoso; 2015). Their income can also be raised by focusing on them as 
enterpreneurs. The activities of designing and implementing income generation opportunities need to be considered throughout the design process (see Figure 1f).
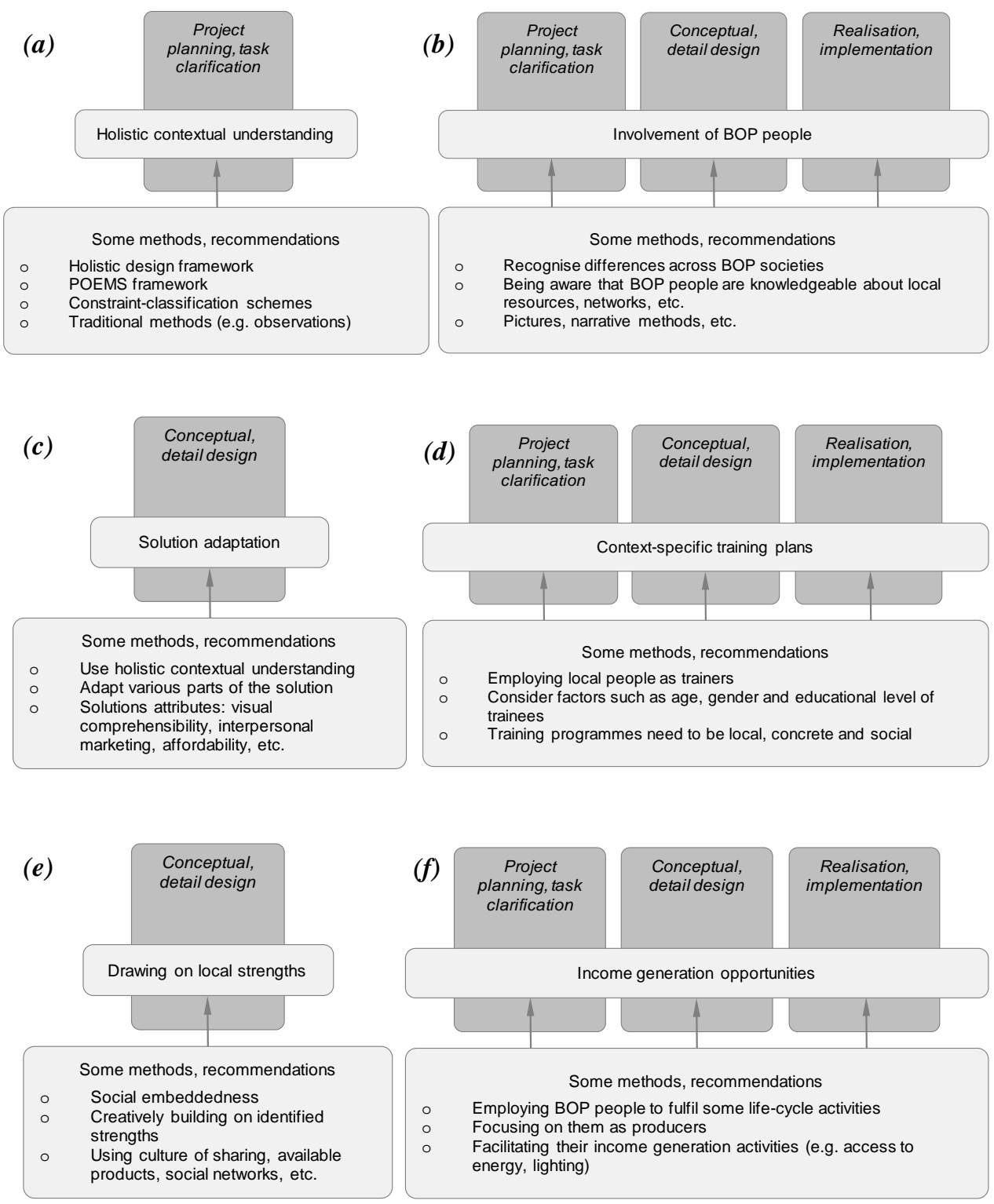

Fig. 1. Key activities and recommendations to support activities in the design and development process 


\subsection{Suitable awareness programmes}

BOP people typically face problems such as illiteracy, knowledge deprivations, and short-changed education (e.g., Jagtap et al., 2013). As a result of these problems, they may face difficulties in reading product labels or selecting a more suitable product option. They may also lack awareness about availability of existing products or benefits of an innovation. As such, innovations for BOP societies must consist of awareness programmes that are appropriate for their life conditions and ways of thinking (e.g., UNDP, 2008). Previous research suggests that appropriate awareness programs support the diffusion of innovations in BOP communities (e.g., Jagtap and Larsson, 2013).

Some studies have offered recommendations for how to design awareness programmes for BOP communities. Such awareness programmes ought to consider pictographic and concrete thinking styles of BOP individuals (e.g., Jagtap and Larsson, 2013). The awareness programmes can also use demonstration strategies - that is demonstrating potential advantages of an innovation, how it works, or how it needs to be used. The activities of designing and implementing suitable awareness programmes need to be considered throughout the design process (see Figure 2a).

\subsection{Implementation of life cycle requirements}

A broad range of individual-, institutional- and structural-level deprivations in BOP societies hinder many activities in the life cycle of an innovation such as implementation, repair, recycling, etc. (UNDP, 2008). When a product needs corrective maintenance, it can be difficult to repair it because of lack of maintenance management or shortage of skilled people to repair a product. Therefore, in designing innovations for BOP societies, it is imperative that design teams devote efforts in identifying and implementing life cycle requirements.

Several scholars have developed recommendations for implementing life cycle requirements in designing innovations for the BOP. Some recommendations center on enhancing product attributes such as reliability and maintainability (e.g., Aranda-Jan et al., 2016; Jagtap et al., 2013). It is also crucial to test innovations in actual setting. Life cycle activities can also be implemented by employing suitable business models such as PSS in which a solution developer remains responsible for life cycle activities (e.g., Lemaire, 2009). The activities of identifying and implementing life cycle requirements need to be considered throughout the design process (see Figure $2 \mathrm{~b}$ ).

\subsection{Cross-sector collaboration}

Designing innovations to support development of BOP societies requires inputs from a broad range of stakeholders such as companies, NGOs and local governments (e.g. UNDP, 2008). Collaboration between such stakeholders is useful to bring together their knowledge and skills in order to address a multitude of value chain gaps in BOP societies (e.g. Jagtap et al., 2013). NGOs, with their social embeddedness in local communities, can contribute towards gaining in-depth understanding of the needs of BOP people (e.g. Rivera-Santos and Rufín, 2010). Local governments can also provide 
important inputs, e.g. dissemination of information about designed solutions, providing subsidies, etc. Companies, with their expertise in technology and business management, can provide inputs in designing and developing products (Jagtap and Larsson, 2019).
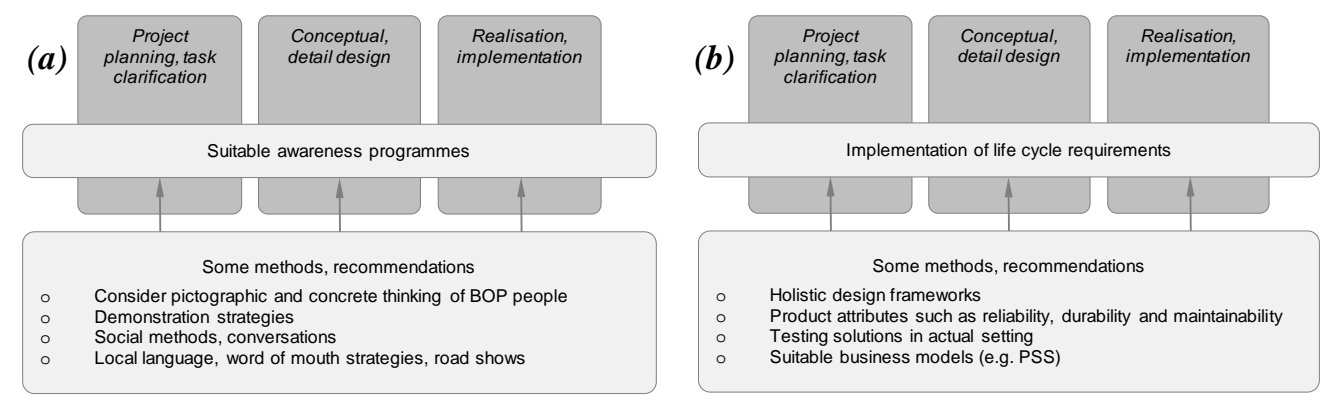

(c)

(d)
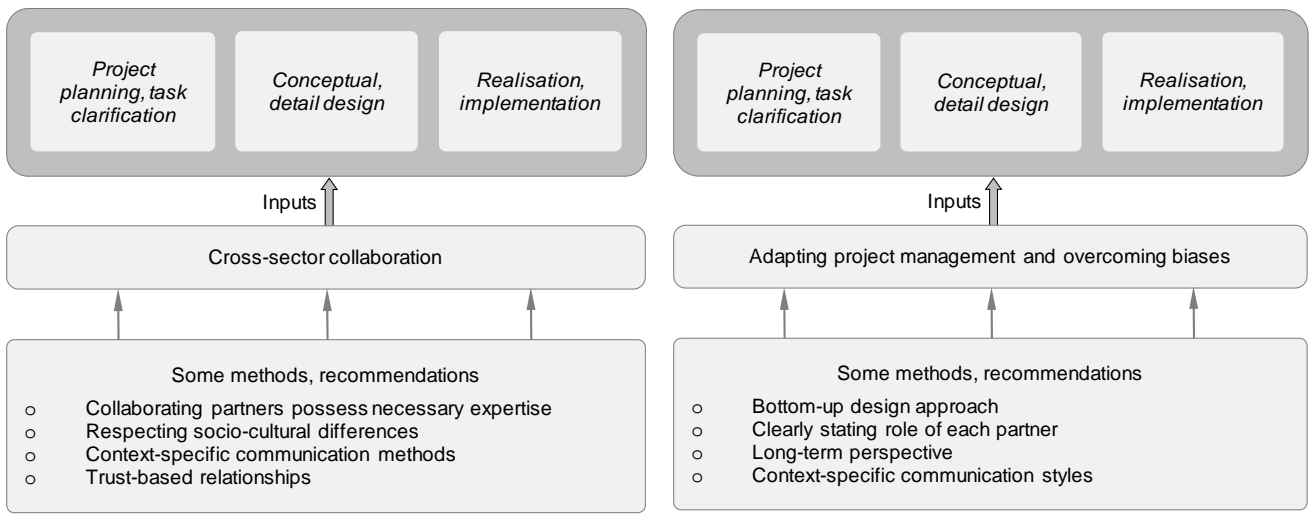

Fig. 2. Key activities, recommendations to support the activities, and phases in the design and development process

The collaborative design between the broad range of partners requires respecting socio-cultural differences between them and employing context-specific communication methods (e.g. UNDP, 2008). In order to ensure effective collaboration between local governments, NGOs and companies, it is crucial to develop and support long-term and trust-based relationships. The involved partners also need to recognise that developing and maintaining partnerships can require long-term operating horizons (e.g., Jagtap et al., 2013). Cross-sector collaboration between companies, NGOS and local governments provides inputs throughout the design and development process (see Figure 2c). 


\subsection{Adapting project management and overcoming biases}

Jagtap et al.'s (2014) study comparing processes of designing products for BOP and non-BOP contexts revealed that designers may handle requirements in a biased manner when they design for the BOP context. For example, they tend to give little attention to requirements about aesthetics and ergonomics despite their applicability in BOP context. Biases can also emerge from the ways in which NGOs, local governments and companies view each other. These partners need to view each other positively. In addition, innovation development for the BOP demands adapting project management to the specificities of the local context (e.g., Jagtap et al., 2014; George et al., 2011).

In project management, the role of each partners needs to be explicitly stated. The involved partners need to adapt communicating styles to local specificities and conditions. The bottom-up approach can also assist stakeholders throughout the design and development process, supporting them to overcome biases and in adapting project management to local context. The activities of adapting project management and overcoming biases serve as inputs throughout the solution development process (see Figure 2d).

\section{Integrated Design Methodology for the BOP}

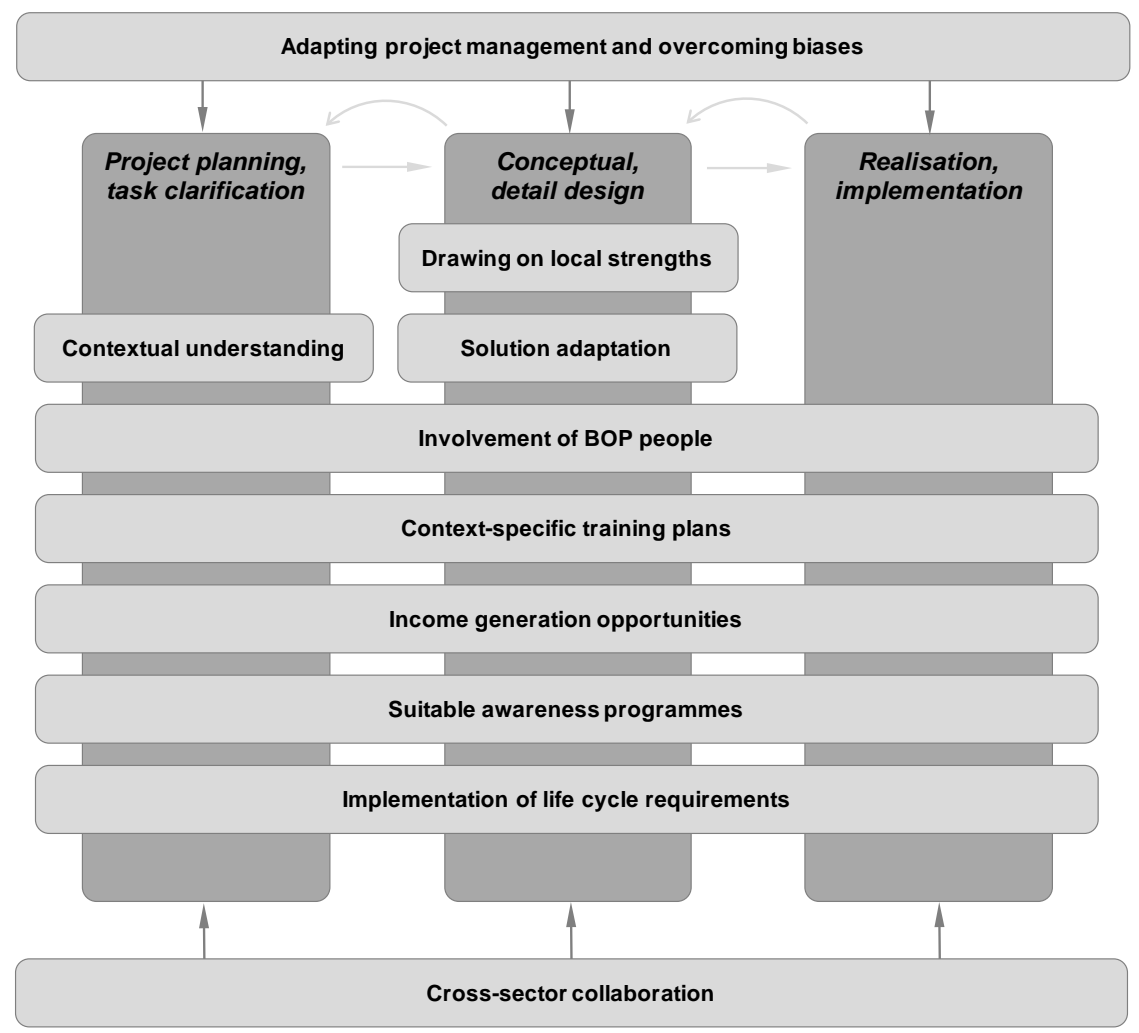

Fig. 3. Frugal-IDeM — Integrated methodology for designing frugal innovations 
Satisfying needs of BOP societies requires integrated innovations. In Sections 2.1 to 2.10, we presented key aspects of designing and developing such innovations. Each of these aspects has been supported by findings of several studies, while providing methods and recommendations for how to implement these aspects. We also related these aspects with the phases in the design and development process. Whilst we presented these aspects in separate subsections in the preceding part of the paper, they are here put together in the form of an integrated design methodology — Frugal-IDeM (see Figure 3). Of the ten aspects, the two aspects - 'cross-sector collaboration' and 'adapting project management and overcoming biases' — provide requisite inputs and resources to undertake various tasks in the process. The remaining eight aspects are about undertaking essential activities in the process.

While some aspects focus on addressing value chain gaps in BOP societies, some focus on leveraging the strengths of these societies. For example, developing contextsensitive awareness and training programmes, creating income generation opportunities, and designing systems to address life cycle activities are key aspects in addressing issues related to weak physical infrastructure, low literacy level of BOP people, their low and uncertain income, etc. Alternatively, aspects of drawing on local strengths and involving BOP people throughout the process build on the strengths of BOP societies.

Some design aspects are about addressing weaknesses or building on strengths of outside partners, who typically come from non-BOP contexts, but contribute towards the design and development of innovations for BOP societies. For example, the outside partners bring in their expertise in design or technology. On the other hand, biases (if any) of outside partners or their lack of knowledge about BOP societies are addressed by understanding the local context holistically and by co-designing with BOP people.

\section{Conclusions}

Integrated innovations are necessary to satisfy needs of BOP people. We identified ten key aspects of designing such integrated innovations. These aspects are related to various phases in the design and development process, while offering methods and recommendations for their effective implementation. Innovations for the BOP ought to be adapted to the specificities of the local context by grounding them in the holistic contextual understanding. To enhance acceptance of these innovations, their design needs to be drawn on local strengths and resources, with the involvement of BOP people throughout the process. Since designing such innovations warrants tackling a variety of constraints, their design requires context-specific training and awareness plans, income generation avenues, and implementation of life cycle requirements. Designing such innovations necessitates inputs from a broad range of partners, and demands adaptation of project management to local specificities, with a significant need to avoid biases. Based on the ten key aspects, we developed a unified methodology for designing integrated frugal innovations. Future studies can test and refine the methodology, for example, by seeking feedback of relevant stakeholders or by its implementation. 


\section{References}

1. Aranda-Jan, C., Jagtap, S., \& Moultrie, J. (2016). Towards a framework for holistic contextual design for low-resource settings. International Journal of Design, 10(3), 43-63.

2. Devisscher, T., \& Mont, O. (2008). An analysis of a product service system in Bolivia: coffee in Yungas. International Journal of Innovation and Sustainable Development, 3(3-4), 262-284.

3. Ernst, H., Kahle, H. N., Dubiel, A., Prabhu, J., \& Subramaniam, M. (2015). The antecedents and consequences of affordable value innovations for emerging markets. Journal of Product Innovation Management, 32(1), 65-79.

4. George, C., Shams, A. N., \& Dunkel, F. V. (2011). Lessons learned in an international service-learning collaborative: Shea butter case study. NACTA Journal, 55(2), 71-77.

5. Jagtap, S. (2019a). Design and Poverty: A Review of Contexts, Roles of Poor People, and Methods. Research in Engineering Design, 30(1), 41-62.

6. Jagtap, S. (2019b). Key Guidelines for Designing Integrated Solutions to Support Development of Marginalised Societies. Journal of Cleaner Production, 219, 148-165.

7. Jagtap, S. (2019c). Design creativity: Refined method for novelty assessment. International Journal of Design Creativity and Innovation, 7(1-2), 99-115.

8. Jagtap, S. and P. Kandachar (2010). Representing Interventions from the Base of the Pyramid. Journal of Sustainable Development, 3(4), 58-73.

9. Jagtap, S., \& Larsson, T. (2019). Resource-Limited Societies, Integrated Design Solutions, and Stakeholder Input. She Ji: The Journal of Design, Economics, and Innovation, 5(4), 285303.

10. Jagtap, S., A. Larsson (2013). Design of product service systems at the base of the pyramid. In: Chakrabarti A, Prakash RV, editors. ICoRD'13. Lecture Notes in Mechanical Engineering: Springer India; p. 581-92.

11. Jagtap, S., A. Larsson, et al. (2013). Design and development of products and services at the Base of the Pyramid: a review of issues and solutions. International Journal of Sustainable Society, 5(3), 207-231.

12. Jagtap, S., Larsson, A., Hiort, V., Olander, E., Warell, A. \& Khadilkar, P. (2014). How design process for the Base of the Pyramid differs from that for the Top of the Pyramid. Design Studies, 35(5), 527-558.

13. Lemaire, X. (2009). Fee-for-service companies for rural electrification with photovoltaic systems: The case of Zambia. Energy for sustainable development, 13(1), 18-23.

14. Letaifa, S., \& Reynoso, J. (2015). Toward a service ecosystem perspective at the base of the pyramid. Journal of Service Management, 26(5), 684-705.

15. López, A. M., Musonda, F., Sakao, T., \& Kebir, N. (2017). Lessons learnt from designing PSS for Base of Pyramid. Procedia CIRP, 61, 623-628.

16. Murcott, S. (2007). Co-evolutionary design for development: influences shaping engineering design and implementation in Nepal and the global village. Journal of International Development, 19(1), 123-144.

17. Nakata, C., \& Weidner, K. (2012). Enhancing new product adoption at the base of the pyramid: a contextualized model. Journal of Product Innovation Management, 29(1), 21-32.

18. Nieusma, D. (2004). Alternative design scholarship: Working toward appropriate design. Design Issues, 20(3), 13-24.

19. Prahalad, C. K. (2004). The fortune at the bottom of the pyramid: Eradicating poverty through profits. Upper Saddle River: NJ: Wharton School Publishing.

20. Rivera-Santos, M., \& Rufín, C. (2010). Global village vs. small town: Understanding networks at the Base of the Pyramid. International Business Review, 19(2), 126-139 
21. UNDP (2008). Creating Value for All: Strategies for Doing Business with the Poor. United Nations Development Programme.

22. Whitney, P., \& Kelkar, A. (2004). Designing for the Base of the Pyramid. Design Management Review, 15(4), 41-47. 